\title{
1997 CALL For PAPERS
}

\section{Guidelines For Participation}

When submitting panel and individual paper proposals keep in mind the five participation rules developed by the APSA Council:

1. Participation Limitation

In the Fall of 1987, in order to provide opportunities to participate in the Annual Meeting by the greatest number of people, the APSA Council limited participation in the Program. As a result, presenters are limited to TWO APPEARANCES on sessions organized by the APSA Program Committee, Organized Section, and Related Group panels.

An appearance on the Annual Meeting Program takes the form of chair, paper or roundtable presenter, or discussant.

2. Preregistration

The APSA Council requires all program participants to preregister by June 15, 1996. Participants who do not preregister by June 15 will not be listed in the Final Program.

\section{Exempt Participants}

Prospective participants may request of a division chair or program organizer an exemption from the preregistration requirement if they are: a) not a political scientist; b) appearing on only one panel; and c) not an exempt participant in 1996. An exempt participant receives a badge for admission to all Annual Meeting activities, but will not receive an Annual Meeting Program or the reduced hotel rate.

\section{Paper Delivery}

As paper presenters you have two important obligations: a) to ensure that the members of your panel, especially discussants, receive your paper in time to read it carefully prior to the meetings, and b) to submit $\mathbf{5 0}$ copies of the paper to the panel paper room at the hotel by the first day of the meetings.

\section{Panel Schedule}

Panels are scheduled in fourteen (14) time slots beginning at 8:45 a.m. on Thursday and concluding at 12:30 p.m. on Sunday. Participants are expected to be available for any of the fourteen time slots. If your schedule is limited by a teaching or travel constraint, inform the division chair or program organizer upon your acceptance as a participant. 


\section{Proposal Submission Process}

APSA will revise the proposal submission process for the 1997 Annual Meeting in order to reduce the administrative burden placed on the members of the Program Committee. In the past, panel and paper proposals were submitted directly to a program division chair. For the 1997 meeting, all proposals should be sent to APSA. The Association meeting staff will accumulate and organize the submissions for each program division, acknowledge receipt of proposals, and forward the proposals to the appropriate division chairs in December.

Please review "Guidelines for Participation," and pay special attention to the new submission instructions below.

1. Paper or panel proposals must be accompanied by the appropriate form. Please be sure you type or print clearly.

Electronic submissions will not be accepted for the 1997, but will be a accepted for the 1998 meeting.

2. It is very important that you indicate the division(s) to which you are submitting your proposal(s). Multiple submissions of proposals are strongly discouraged. You may submit each panel or paper proposal to no more than two divisions. Include two copies of your proposal for each division to which you are applying.

Send proposals to:

APSA 1997 Proposal

1527 New Hampshire Ave, NW

Washington, DC 20036

3. Your submission will be acknowledged by APSA within two weeks of receipt.

4. You will be notified of your proposal's acceptance or rejection by program division chairs before February 1, 1997. 


\section{Participation Guidelines for Related Groups}

Professional groups engaged in the study of political science, unaffiliated with the American Political Science Association, are invited to participate in the Annual Meeting as Related Groups. Related Groups are subject to the following guidelines:

1. An unaffiliated group may participate in the APSA Annual Meeting as a Related Group if its purpose is to promote teaching and research in political science. A first time participating group must include a description of the group's purposes with its request for panels.

2. A Related Group's event may be canceled by the Association if the event does not further research and teaching in political science or the professional development of political scientists.

3. As with the APSA Program Committee, it is expected that over the years related groups will rotate responsibility for organizing their panels to insure the widest possible participation of individuals and the broadest possible representation of perspectives and methodologies.

4. APSA official events have priority on space assignment, scheduling and changes. Confirmed Related Group space may be changed to accommodate the needs of the Program Committee.

\section{Send Panel Requests To}

Related Groups

American Political Science Association

1527 New Hampshire Avenue, NW

Washington, DC 20036 